\title{
Relative Response of Indigenous Rice Genotypes to Low Versus Normal Planting Density for Determination of Differential Phenotypic Plasticity in Traits Related to Grain Yield
}

\author{
Tokee M. Tareq, M. Sazzadur Rahman ${ }^{1}$, Nurnabi A. Jewel, \\ Tasmia Islam ${ }^{2}$, Hiroyuki Shimono ${ }^{3}$ and Zeba I. Seraj* \\ Department of Biochemistry and Molecular Biology, University of Dhaka, Bangladesh
}

Key words: Climate change, $\left[\mathrm{CO}_{2}\right]$ increase, Relative response, Phenotypic plasticity

\begin{abstract}
Increase in atmospheric $\mathrm{CO}_{2}\left(\left[\mathrm{CO}_{2}\right]\right)$ improves the efficiency of the unsaturated photosynthetic system of $\mathrm{C}_{3}$ plants, like rice, which leads to high crop productivity and increased biomass production. Planting geometry using lower than standard planting density has been shown to be an alternative pre-screening technique for phenotypic plasticity as a proxy of $\left[\mathrm{CO}_{2}\right]$ responsiveness. More than 200 indigenous rice genotypes were tested for several traits, such as plant height, tiller number, panicle number, panicle dry weight, straw dry weight, total dry weight and harvest index. Their relative response for these phenotypic traits at low density planting versus normal density was determined to assess the plasticity of the genotypes. Ten genotypes were identified as significantly $\left[\mathrm{CO}_{2}\right]$ responsive based on their higher panicle dry weight and panicle number. Even though it was observed that genotypes with higher days to maturity (DM) were more plastic, rice genotypes with low DM had a significantly higher relative response to harvest index, implying that rice with low DM may also be considered to be responsive to higher $\left[\mathrm{CO}_{2}\right]$. In order to associate phenotypic plasticity with the genotype, 23 SSR markers physically close to genes involved in $\mathrm{CO}_{2}$ metabolism were used to amplify selected responsive and non-responsive rice. Out of 3 alleles amplified using RM17, allele A was found to be significantly associated with genotypes with higher phenotypic plasticity whereas allele $C$ was associated with genotypes with negligible response. The identified rice genotypes and the associated marker RM17 can therefore be tested further for breeding of superior rice responsive to higher $\left[\mathrm{CO}_{2}\right]$ envisaged in a changing climatic scenario of the future.
\end{abstract}

*Author for correspondence: <zebai@du.ac.bd>. ${ }^{1}$ Plant Physiology Division, Bangladesh Rice Research Institute, Gazipur, Bangladesh. ${ }^{2}$ Department of Biochemistry and Molecular Biology, Jagannath University, Dhaka, Bangladesh. ${ }^{3}$ Crop Science Laboratory, Faculty of Agriculture, Iwate University, Morioka, Iwate, Japan. 


\section{Introduction}

Rice accounts for maximal human consumption as a staple food by three billion people and provides $20 \%$ calorie requirement of the world population (Chaturvedi et al. 2017, Jasim et al. 2018). Although the current production of rice is enough to feed the world population, only $72 \%$ of the global demand of rice can be met by 2050, assuming a continuous and steady yield enhancement rate (Ray et al. 2013, Srinivasan et al. 2017). To overcome the yield and demand gap, increasing the cultivation area is not a viable option, as the current cultivable land for rice production is already in under constant pressure of urbanization and land degradation. These leaves increasing yield per unit land area as the only suitable solution (Long 2014, Srinivasan et al. 2017). But like other grains, gain in rice productivity increase has stagnated in the last two decades (Zhang et al. 2014, Paleari et al. 2017). Use of plant dwarfism as ideal plant architecture as exemplified in the green revolution, has already reached its biological limit and has little room for improvement (Zhu et al. 2010, Srinivasan et al. 2017). Moreover, climate change also poses both abiotic and biotic threats, like drought, heat, salinity, sea level rise, new predatory insects, pesticide resistant pests as well as elevated level of greenhouse gases like $\mathrm{CO}_{2}$ (Kant et al. 2012, Amin et al. 2016). The drastic change in the level of atmospheric $\mathrm{CO}_{2}\left(\left[\mathrm{CO}_{2}\right]\right)$, primarily caused by the industrial revolution which is predicted to increase by almost $50 \%$ by mid-century due to anthropogenic changes (Shimono et al. 2014, Bishop et al. 2015). Elevated $\mathrm{CO}_{2}\left(\mathrm{e}\left[\mathrm{CO}_{2}\right]\right)$ is well known to have a positive effect on the $\mathrm{C} 3$ plants, called " $\left[\mathrm{CO}_{2}\right]$ fertilization effect" (Long 2014, Chaturvedi et al. 2017). Increase in atmospheric $\mathrm{CO}_{2}\left(\left[\mathrm{CO}_{2}\right]\right)$ improves the efficiency of the unsaturated photosynthetic system of $\mathrm{C}_{3}$ plants, like rice, which leads to high crop productivity and increased biomass production (Bishop et al. 2015, Tausz-Posch et al. 2015).

Beside the enhancement of reproductive and vegetative growth, elevated atmospheric $\mathrm{CO}_{2}\left(\mathrm{e}\left[\mathrm{CO}_{2}\right]\right)$ is found to improve water use efficiency and lower photo-respiratory losses of rice (Leakey 2009, Srinivasan et al. 2017). Several studies have been conducted to assess the extent of the positive effect of e[ $\left[\mathrm{CO}_{2}\right]$ on $\mathrm{C}_{3}$ crops including rice (Hasegawa et al. 2013, Shimono et al. 2014, Zhu et al. 2014), wheat (Ziska 2008, Tausz-Posch et al. 2015) and soybean (Bishop et al. 2015, Bunce 2015, Kumagai et al. 2015). These studies have documented tremendous diversity in $\mathrm{e}\left[\mathrm{CO}_{2}\right]$ responsiveness, as the yield increase differ among species and subspecies, even varieties (Kumagai et al. 2015, Tausz-Posch et al. 2015). Moreover, the selection procedure in breeding technology of rice varieties does not include efficient $\left[\mathrm{CO}_{2}\right]$ utilization property, and as a consequence, more recently developed commercial varieties have been found to 
have either same or lower responsiveness to e[CO $\left.\mathrm{CO}_{2}\right]$ compared to commercial varieties of distant past (Ainsworth et al. 2008, Ziska et al. 2012). So, active intervention for genotypes that respond strongly to e[CO $\left.\mathrm{CO}_{2}\right]$ will be essential for maintaining food security in future (Kumagai et al. 2015).

For directly studying the e $\left[\mathrm{CO}_{2}\right]$ utilization efficiency of rice varieties, Free Air $\mathrm{CO}_{2}$ Enrichment (FACE) system has been proven to be the best option, without any limitations of the traditional control-environment chamber systems such as reduced sunlight, warmer temperature and increased vapor pressure (Long et al. 2004). But such elaborate and sophisticated facilities are not suitable to screen the germplasms of the diverse collection of the agronomic crops, especially not for highly stratified cultivars such as rice (Shimono 2011, Shimono et al. 2014). (Shimono 2011) introduced a simple and novel idea to use planting geometry as an alternative pre-screening technique by using phenotypic plasticity as a proxy of $\left[\mathrm{CO}_{2}\right]$ responsiveness. Phenotypic plasticity is defined as the ability of changing physiological, molecular or metabolic performance of a genotype to cope up with the heterogeneous environmental variation (Price et al. 2003, Kikuchi et al. 2017). As plants grown at low density face reduced competition for solar radiation, water and soil nutrients, and as a consequence, plants with greater plasticity are able to adapt and utilize this resourceful environmental condition more efficiently (Kumagai et al. 2015, MolinaMontenegro et al. 2016). In terms of resource enrichment, the response of the phenotypic plasticity of plants in low density planting should mimic the response towards e[CO $\mathrm{CO}_{2}$ (Kumagai et al. 2015, Kikuchi et al. 2017). The proposed similar behavior of phenotypic plasticity and $\mathrm{e}\left[\mathrm{CO}_{2}\right]$ responsiveness has been applied and confirmed for rice in terms of panicle number (Shimono et al. 2014) and for soybean in terms of seed yield (Kumagai et al. 2015).

In this study, we used low planting density as a pre-screening method to assess the growth potential of local varieties in a resource rich environment. So far, no previous studies have been reported in Bangladesh which screened rice landraces for their phenotypic plasticity. Phenotypic plasticity is conferred by the ability to adapt by changing the physiochemical attributes in response to environmental change. Therefore, indigenous rice landraces are the most suitable for conducting such an experiment, because they are better adopted to our climate and soil environment. A specific set of varieties with the most and least phenotypic plasticity were further subjected to molecular characterization. A total of 23 polymorphic SSRs were used to evaluate the previously determined candidate genetic loci, which were selected based on their proximity of nucleotide distance. 


\section{Materials and Methods}

Two hundred and two Bangladeshi local varieties and 6 high yielding varieties were selected. These include BRRI Gene Bank Accessions 1-463 from which 202 genotypes were selected based on the following criteria. The local landraces were chosen to include, 154 of T. Aman, 11 of Boro and 37 of Aus varieties. Deepwater rice and Broadcast Aman rice were excluded due to their low tillering capacity and excessive lodging. BRRI high yielding varieties and 4 other stress resistant varieties were included in this study as control to compare the plasticity of the modern cultivars. Seed germination and seedling growth was carried out in seedbeds at the Bangladesh Rice Research Institute (BRRI). After 3 weeks, seedlings were transplanted in fields of BRRI by hand at two different densities normal and low density. Normal density (ND) was 25 plants $/ \mathrm{m}^{2}$ with $20 \mathrm{~cm}$ between rows and $20 \mathrm{~cm}$ between plants. In low density, the density of plant per area was reduced into 12.5 plants $/ \mathrm{m}^{2}$ by doubling the distance between plants. To randomize the planting, ALPHA-lattice design were followed for designing the field position of transplanted seedlings (Patterson and Williams 1976). In
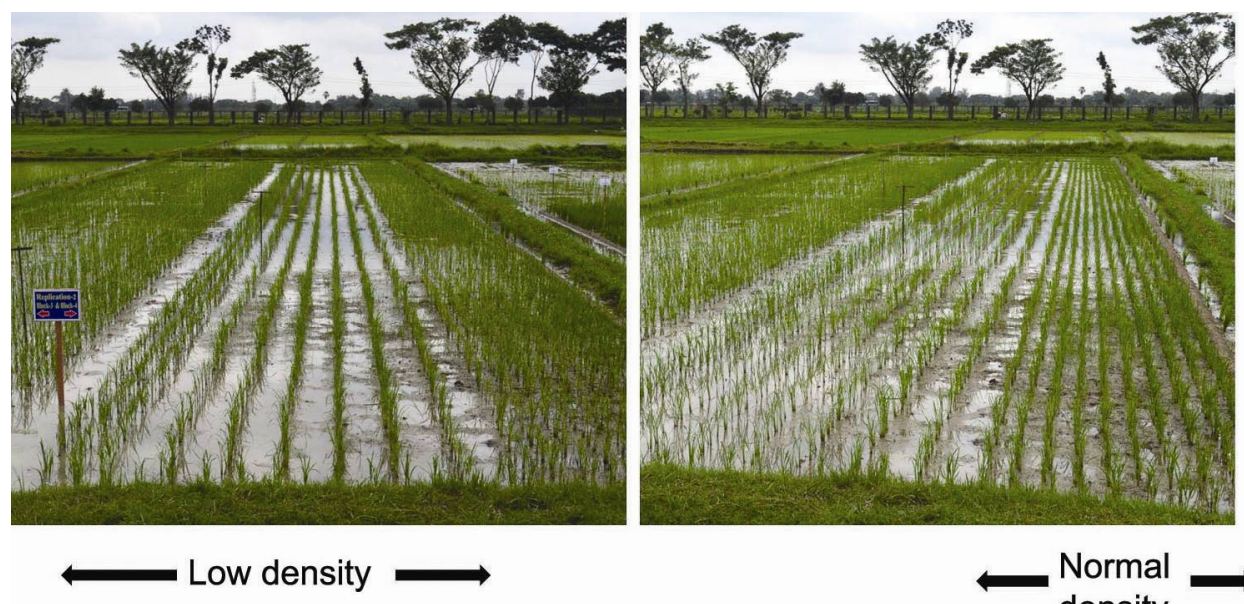

Fig. 1. The picture of the BRRI field at the early stage of the planting. The pictures show difference between two planting densities - low density planting (left picture, center) and normal density planting (right picture, right side).

each density planting, 24 seedlings were transplanted for growing. So, for a single replicate 48 seedlings ( 24 plants * 2 different density) were grown in two density, shown in Fig. 1. All the phenotypic experiment was conducted in fields at BRRI. For assessment of the phenotypic traits of the plants such as, two replicates were used, 8 plants per replicate. Number of tillers were counted from the selected 8 plants and then the average were measured as the representative 
tiller number. Plant height was measured from base to the tip of spikelet of the longest tiller in $\mathrm{cm}$. After harvesting, panicles and straws were separately dried in an oven of 500 and $50^{\circ} \mathrm{C}$ for 5 days, respectively before measuring the weight. Sum of panicle and straw dry weights was considered as total dry weight. The ratio of panicle dry weight and total dry weight is commonly known as 'harvest index'. This particular trait represents actual yield relative to plant growth. Positive gains in yield components and biomass in low density planting in comparison with high density planting is used as a measure of phenotypic plasticy. Therefore the ratio of a specific phenotypic parameter of the low density planting and normal density planting (LD : ND) is considered as the 'relative response' of a particular genotype (Kikuchi et al. 2017). The performed analysis was conducted to evaluate the range of the relative responses of the traits as well as to compare the two different maturity group. Genotype which responded/not respond to the higher $\mathrm{CO}_{2}$ were selected from this study.

Genomic DNA was isolated from (0.5 - $1.0 \mathrm{~g})$ pooled leaf tissue of selected 36 accessions using the modified CTAB method (Doyle and Doyle 1987). A total of 23 genes were selected for polymorphism analysis, which were found to be highly expressed in elevated $\left[\mathrm{CO}_{2}\right]$ (Fukayama et al. 2009, Fukayama et al. 2011). Moreover, three associated SNP QTLs were also included, found by (Kikuchi et al. 2017). The 23 SSR markers were selected based on their close proximity with these associated loci. The physical distance (in $\mathrm{Mb}$ ) between the target loci and corresponding SSR shown in the Table 2. Polymerase chain reaction (PCR) was performed using $50 \mathrm{ng}$ template DNA, $0.1 \mathrm{mM}$ dNTPs, $0.33 \mu \mathrm{M}$ of forward and reverse primers each, $1.6 \mathrm{mM} \mathrm{MgCl}, 1 \times \mathrm{PCR}$ buffer, $2.6 \% \mathrm{DMSO}$, and 0.5 unit of recombinant Taq polymerase (Invitrogen). The mixture was then denatured at $95^{\circ} \mathrm{C}$ for $5 \mathrm{~min}$, followed by 35 cycles of denaturation at $95^{\circ} \mathrm{C}$ for 1 $\mathrm{min}, 1 \mathrm{~min}$ of annealing at $55-60^{\circ} \mathrm{C}$ (depending on primer's $\mathrm{Tm}$ ), $1 \mathrm{~min}$ of extension at $72^{\circ} \mathrm{C}$ with a final extension step at $72^{\circ} \mathrm{C}$ for $7 \mathrm{~min}$. The $23 \mathrm{RM}$ markers were obtained commercially from idt-1st base, Singapore. The amplified PCR products were resolved and visualized in non-denaturing $10 \%$ polyacrylamide gel electrophoresis. The gels were stained in $\mathrm{EtBr}$ and visualized with alpha imager gel documentation system. The primary assessment of polymorphism was done using the PowerMarker V3.25 software (Liu et al. 2005). All the analysis and data visualization were performed in $\mathrm{R}$ version 3.3.3 (Team 2014). All the plots in this study were visualized using "ggplot2" package of $R$ (Wickham 2009). 


\section{Results and Discussion}

The effect of the planting density on the specific response of the plants and the resultant alteration in the phenotypic traits were analyzed. Low density planting reduces competition for resources like water, radiation etc., which mimics the response to elevated $\left(\mathrm{CO}_{2}\right)$. The target of this experiment was to identify the most responsive cultivars as well as to determine the extent and type of the phenotypic differences that were generated.

The comparison of phenotypes between low density and normal planting clearly demonstrated that all the traits except plant height and harvest index increased highly significantly $\left(\mathrm{p}<2.2^{*} 10^{-16}\right)$ at low density planting (Table 1$)$. The phenotypic distribution of the two planting densities is shown in Fig. 2A. We used the ratio of phenotypic traits at low density versus normal density or the relative response of a trait as an indicator of elevated phenotypic plasticity. The average relative response of different phenotypic parameters ranged from 0.89 to 1.93 (Table 1). Among all the observed phenotypes, the largest average relative response was found for straw dry weight which was increased by approximately 2 times (1.93) with a maximum value of 3.01. This means that the plasticity of rice plants is most strongly associated with vegetative growth. The harvest index, defined as the ratio of panicle dry weight and total dry weight, is considered one of the very important agronomic traits. Although statistically insignificant, nine cultivars showed a relative increase of harvest index greater than 1.1 (10\% increase at low density). The cultivar 'SHUL KUMOR' showed the highest response in harvest index (1.67). Thus plasticity of this particular phenotype may be rare, but was still found in one of the landraces. The individual range of the traits are shown in Fig. 2B.

The relative responses of these phenotypes were further analyzed for their inter-relation. For this a correlation and clustering analysis were performed in R. The result of these analyses are shown in Fig. 2C. Maximum correlation (0.92) was found between straw dry weight (SDW) and total dry weight (TDW), followed by the correlation (0.75) between total dry weight (TDW) and panicle dry weight (PDW) and correlation (0.70) between panicle dry weight (PDW) and panicle number $(\mathrm{PN})$. These data suggest that relative response of these four phenotypes (PN, PDW, SDW and TDW) are strongly related with each other. Cluster analysis also gave the same result. Plant height $(\mathrm{PH})$ and tiller number (TL) have lower correlation with other phenotypes, indicating presence of a separate response type (TL) or no response at all (PH).

Maturation time is the interval of time between the day of sowing the seedlings and the day of heading (the state of plant with visible panicle). Among the 208 accessions (202 landraces and 6 BRRI high yielding varieties) maturation 
date varied from 69 days to 124 days. For grouping the accessions with such a wide range of maturation time, we considered accessions which required less than 95 days to heading as early maturing cultivars and the others as late maturing cultivars. After dividing the accessions into early maturity and late maturity group, we compared the relative response of the phenotypic traits with each other. The accessions of late maturity group (LMG) showed better response in almost all the phenotypes, as indicated in Fig. 2D. Except for plant height, all the differences are statistically significant. On the other hand, early maturity group showed better performance in case of harvest index (HI). Such outcome can be attributed to interrelation of plants with respect to grain filling and leaf senescence as well as 'carbohydrate sink' hypothesis of photosynthetic acclimation (Yang and Zhang 2006).

Table 1. Position of the target loci and their closely linked SSR markers.

\begin{tabular}{|c|c|c|c|c|c|}
\hline $\begin{array}{c}\text { Chromosome } \\
\text { number }\end{array}$ & Loci & $\begin{array}{l}\text { Position } \\
(\mathrm{Mb})\end{array}$ & SSR marker & $\begin{array}{l}\text { Position } \\
(\mathrm{Mb})\end{array}$ & $\begin{array}{l}\text { Physical distance } \\
(\mathrm{kb})\end{array}$ \\
\hline \multirow{4}{*}{1} & AK071246 & 19.63 & RM129 & 19.01 & 626.93 \\
\hline & CI333262 & 23.34 & RM9 & 23.32 & 21.74 \\
\hline & AK102220 & 37.08 & \multirow{2}{*}{ RM11918 } & \multirow{2}{*}{37.33} & 246.19 \\
\hline & AJ308374 & 37.09 & & & 238.07 \\
\hline \multirow{7}{*}{2} & AK072245 & 0.34 & RM3340 & 0.39 & 44.30 \\
\hline & AK121261 & 30.23 & RM530 & 30.56 & 329.31 \\
\hline & AK072292 & 5.65 & RM545 & 4.92 & 735.12 \\
\hline & AK102392 & 8.27 & RM218 & 8.38 & 101.95 \\
\hline & & & RM14723 & 9.19 & 122.63 \\
\hline & qER1 & 9.32 & RM14759 & 9.73 & 408.55 \\
\hline & & & RM232 & 9.75 & 437.57 \\
\hline \multirow[t]{6}{*}{3} & AK071595 & 17.60 & \multirow{2}{*}{ RM15245 } & \multirow{2}{*}{17.63} & 37.78 \\
\hline & CI560567 & 17.98 & & & 341.31 \\
\hline & AK106398 & 25.83 & \multirow{2}{*}{ RM15630 } & \multirow{2}{*}{25.88} & 51.95 \\
\hline & AU057193 & 26.41 & & & 529.54 \\
\hline & AF058697 & 31.79 & RM15999 & 31.88 & 94.36 \\
\hline & Os03g0830200 & 35.72 & RM16201 & 35.68 & 42.51 \\
\hline \multirow[t]{2}{*}{4} & AK069195 & 26.94 & RM17282 & 26.69 & 253.32 \\
\hline & AB062676 & 2.92 & RM204 & 3.17 & 246.83 \\
\hline \multirow[t]{2}{*}{6} & qER2 & 5.07 & RM314 & 4.84 & 222.99 \\
\hline & AK108566 & 15.20 & RM20046 & 15.88 & 674.86 \\
\hline \multirow{2}{*}{7} & AK108625 & 1.78 & \multirow{2}{*}{ RM436 } & \multirow{2}{*}{2.55} & 774.12 \\
\hline & AK120691 & 2.49 & & & 65.22 \\
\hline 10 & AK066625 & 0.77 & RM24904 & 0.86 & 92.26 \\
\hline \multirow{2}{*}{11} & AF017359 & 0.69 & \multirow{2}{*}{ RM3863 } & \multirow{2}{*}{0.91} & 213.63 \\
\hline & AK064966 & 1.60 & & & 692.59 \\
\hline \multirow{2}{*}{12} & AK073742 & 26.58 & RM28746 & 26.40 & 176.63 \\
\hline & qER3 & 26.58 & RM17 & 27.02 & 443.83 \\
\hline
\end{tabular}




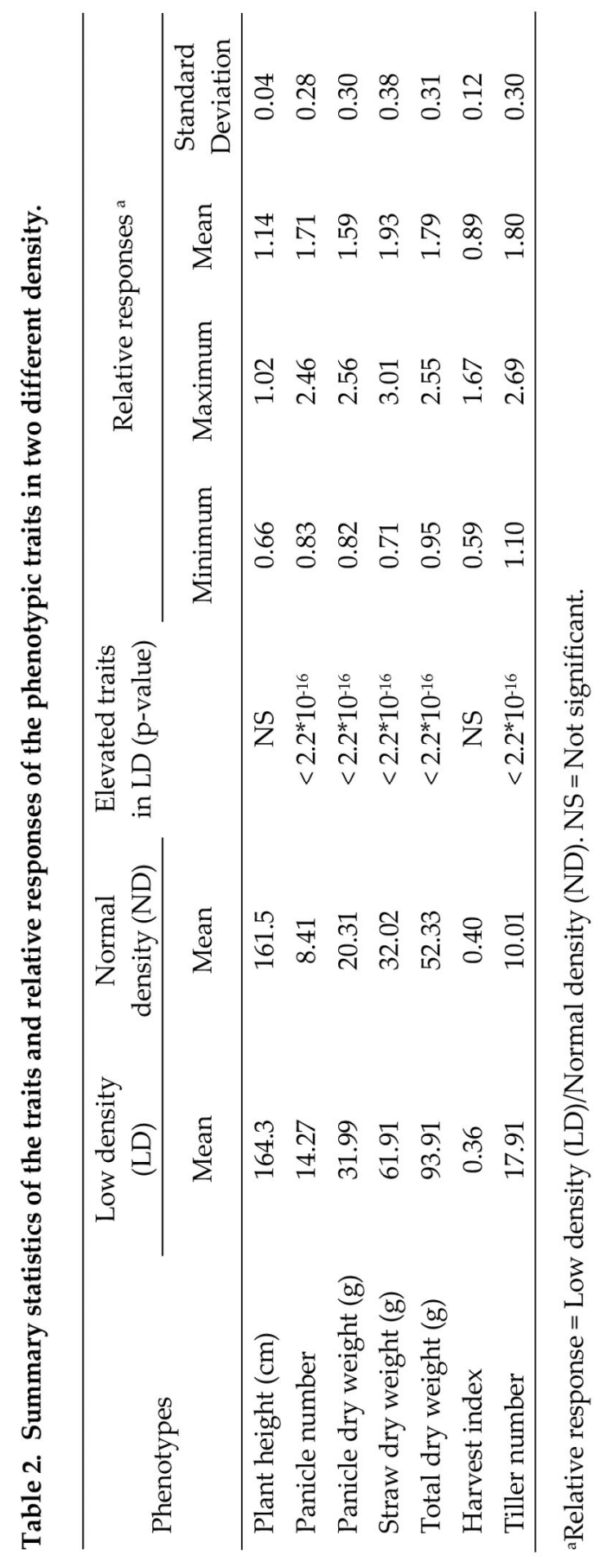




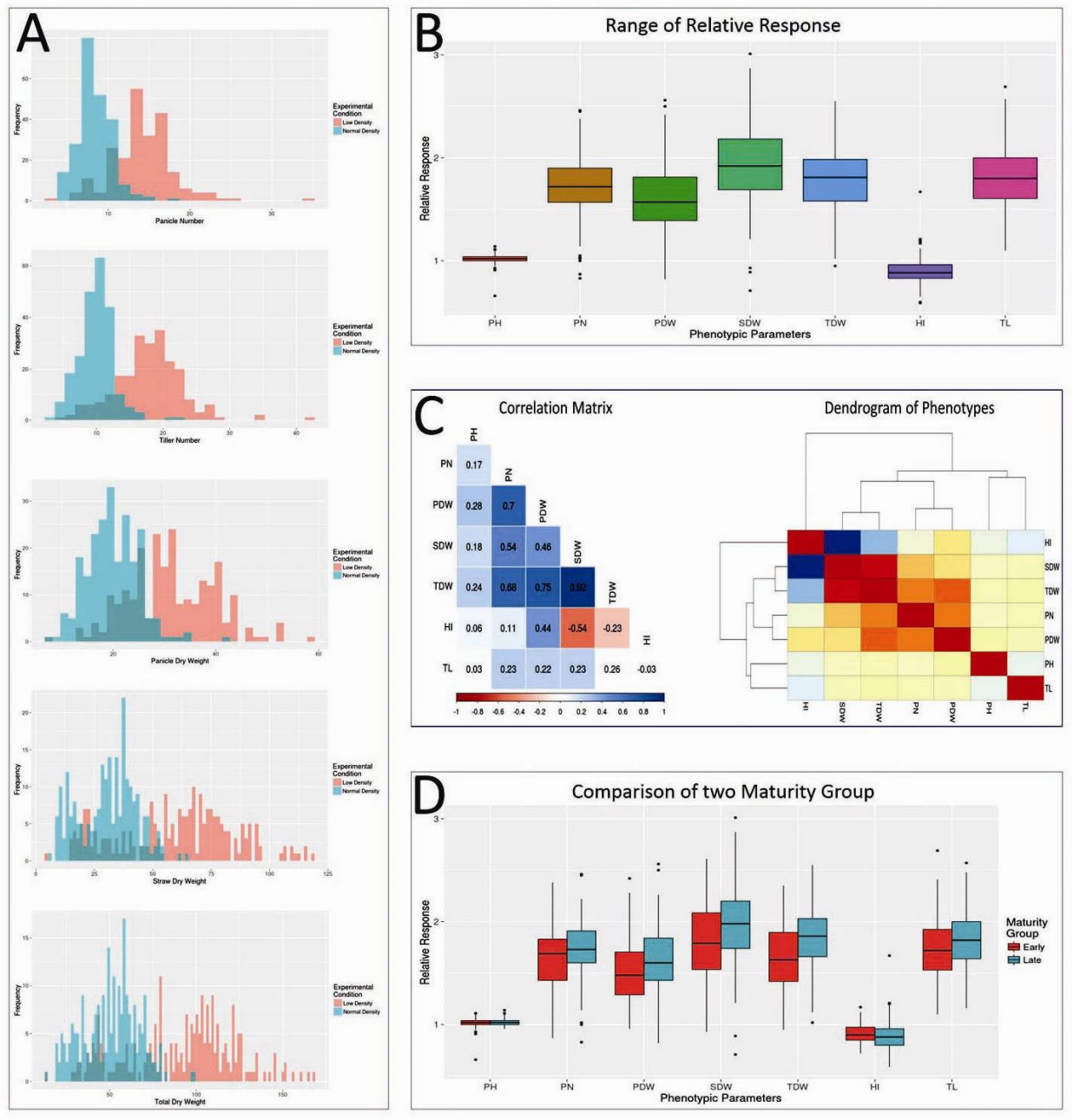

Fig. 2. A. Frequency of the increased phenotypic responses at low density compared to normal density for five traits including panicle number, tiller number, panicle dry weight, straw dry weightand total dry weight. In each plot, the two different colors indicate two different planting densities (light red for low density and light blue for normal density). B. Range of the relative responses of phenotypic plasticity of different traits $(\mathrm{PH}=$ Plant Height, $\mathrm{PN}=$ Panicle number, PDW = Panicle dry weight, SDW = Straw dry weight, TDW = Total dry weight, $\mathrm{HI}=$ Harvest index, $\mathrm{TL}=$ Tiller number). $\mathrm{C}$. In the correlation matrix, the intensity of the color indicates the level of the correlation in addition to the number and the absence of color indicates correlation is not significant. In the dendrogram of relative response, closely linked phenotypic traits are clustered with each other on the basis of correlation. D. Comparison between the ranges of relative responses of different phenotypic parameters in the context of maturity group.

The cultivars which showed the highest plastic phenotypes were chosen on the basis of their relative increase in traits at low density planting. Altogether 10 accessions were selected on the basis of their superior response for multiple traits. Among the phenotypic traits, response of panicle dry weight and panicle 
number was prioritized while selecting for the most plastic cultivars. Table 3 summarizes the relative response of the examined traits.

Table 3. Relative response of the top 10 culitvars to low planting density.

\begin{tabular}{|c|c|c|c|c|c|c|}
\hline \multirow{2}{*}{$\begin{array}{l}\text { Accession } \\
\text { number } \\
\text { (BRRI) }\end{array}$} & \multirow{2}{*}{$\begin{array}{l}\text { Accession } \\
\text { name }\end{array}$} & \multicolumn{5}{|c|}{ Relative response } \\
\hline & & $\begin{array}{l}\text { Panicle } \\
\text { No. }\end{array}$ & $\begin{array}{l}\text { Panicle } \\
\text { dry wt. } \\
\text { (g/plt) }\end{array}$ & $\begin{array}{l}\text { Straw } \\
\text { dry wt. } \\
\text { (g/plt) }\end{array}$ & $\begin{array}{l}\text { Total } \\
\text { dry wt. } \\
\text { (g/plt) }\end{array}$ & $\begin{array}{l}\text { Tiller } \\
\text { No. }\end{array}$ \\
\hline 30 & HASHIKALMI-DA-26 & 2.38 & 2.42 & 1.90 & 2.14 & 1.53 \\
\hline 78 & KARTIK JHUL & 2.46 & 2.56 & 1.99 & 2.14 & 2.48 \\
\hline 157 & CHINI SAGAR & 2.15 & 1.94 & 2.84 & 2.48 & 2.31 \\
\hline 208 & KOHA BINNI & 2.09 & 2.15 & 2.30 & 2.26 & 1.79 \\
\hline 224 & DEPA DHAN & 2.00 & 2.10 & 2.45 & 2.33 & 2.35 \\
\hline 237 & DUDKAT & 2.06 & 2.02 & 2.58 & 2.35 & 1.80 \\
\hline 263 & SHADA DUMRA & 2.03 & 2.05 & 2.45 & 2.25 & 2.13 \\
\hline 406 & BUTA & 2.18 & 2.15 & 2.49 & 2.34 & 2.42 \\
\hline 419 & SUNA SAIL & 1.88 & 2.50 & 2.16 & 2.28 & 2.19 \\
\hline 463 & RONJAY & 2.03 & 1.99 & 2.22 & 2.14 & 1.64 \\
\hline
\end{tabular}

Simple sequence repeat (SSR) marker analysis is well established in rice due to the higher abundance and polymorphic nature of these markers. A large set of categorized SSR markers are available to analyze the diversity of the rice cultivars. However, as a complex and relatively less studied trait, no direct association of the SSR marker and rice cultivars has been studied yet for $\mathrm{CO}_{2}$ responsiveness. The target loci were identified by an extensive literature mining and we selected those genes which are reported to be upregulated in rice in a $\mathrm{CO}_{2}$ enriched environment (Fukayama et al. 2009, Fukayama et al. 2011). A total of 23 SSR markers were chosen to specifically analyze these target loci. All of these markers were located in a close proximity to target genes ( 700 kbp). Beside this, 3 SNPs were also analyzed, which are found to be strongly associated with $\mathrm{CO}_{2}$ responsiveness (Kikuchi et al. 2017). For investigating the association of the SSR markers with $\mathrm{CO}_{2}$ responsiveness, 36 accessions were selected consisting of 26 and 10 cultivars which exhibited the most and least plasticity, respectively for multiple phenotypes.

All the studied markers showed polymorphism and a total of 102 alleles were found across the 36 accessions with an average of 4.43 . Among the markers, a maximum of 7 alleles were found for RM14723 and RM15245 whereas a minimum of 2 alleles were detected for two markersRM16201 and RM28746. The sample picture of PAGE analysis of RM314 is shown in Fig. 3A. Marker RM9 had the maximum PIC value (0.76) and gene diversity (0.79). 
To evaluate any possible correlation of SSR markers with the relative response in phenotypic plasticity, we conducted a correlation analysis among the markers and relative response in phenotypes. The correlation plot between the SSR markers and the relative response of the traits are shown in Fig. 3B. Other markers, which are located near the other 2 SNPs did not show any particular association. This may have resulted from large genetic distance (more than $3 \mathrm{cM}$ ) between SSR markers and the SNPs. The SSR marker RM17, which was found to have a high correlation with the selected physiological traits produced 3 alleles in our molecular analysis. The three different alleles are designated as allele A, allele B and allele C. Among the 26 cultivars with highest plasticity, 19 were found to have the allele $A$. All five cultivars with allele $C$ were found to be nonplastic. The cultivars containing allele B were found to be distributed in both groups. We classified the 36 cultivars into three different groups based on the allelic distribution and performed distribution analysis of three alleles across different traits, shown in Fig. 3C. In case of panicle number and panicle dry weight, the allele $\mathrm{A}$ and allele $\mathrm{C}$ showed distinctive distribution. Allele $\mathrm{A}$ is more abundant in case of higher plasticity of panicle number (2.0-folds increase) and panicle dry weight (2.0-folds increase). Whereas, allele $\mathrm{C}$ was found with higher abundance in low response of four traits - panicle number (no increase), panicle dry weight (no increase), total dry weight (1.2-folds increase) and straw dry weight (1.5-folds increase). Allele B did not show any relation with any phenotypic response. No allelic variation was found in tiller number, most possibly due to its lower correlation with other traits.

The present study was designed to represent the diversity of the phenotypic plasticity of Bangladeshi local landraces using low density planting. We could successfully identify 10 cultivars with highest level of phenotypic plasticity, which is under investigation for further characterization. For this experiment, all the selected varieties were taken from the indigenous rice landraces. The modern high yielding varieties are genetically more uniform and thus lack phenotypic variation compared to landraces ( $\mathrm{Li}$ et al. 2006, Ziska and Blumenthal 2007). Several studies indicated that high yielding varieties lack phenotypic plasticity and therefore show relatively lower response to e $\left[\mathrm{CO}_{2}\right]$ ( $\mathrm{Li}$ et al. 2006, Ainsworth et al. 2008, Ziska et al. 2012). We also found similar results, where, two high yielding BRRI varieties, which were used as control, showed lower than average plasticity towards resource enrichment.

The present study demonstrated that increased plasticity of panicle number or panicle dry weight in resource enriched low density planting is strongly associated with total dry weight (indicator of biomass), consistent with other studies (Shimono et al. 2008, Shimono and Okada 2013). The phenotypic plasticity 


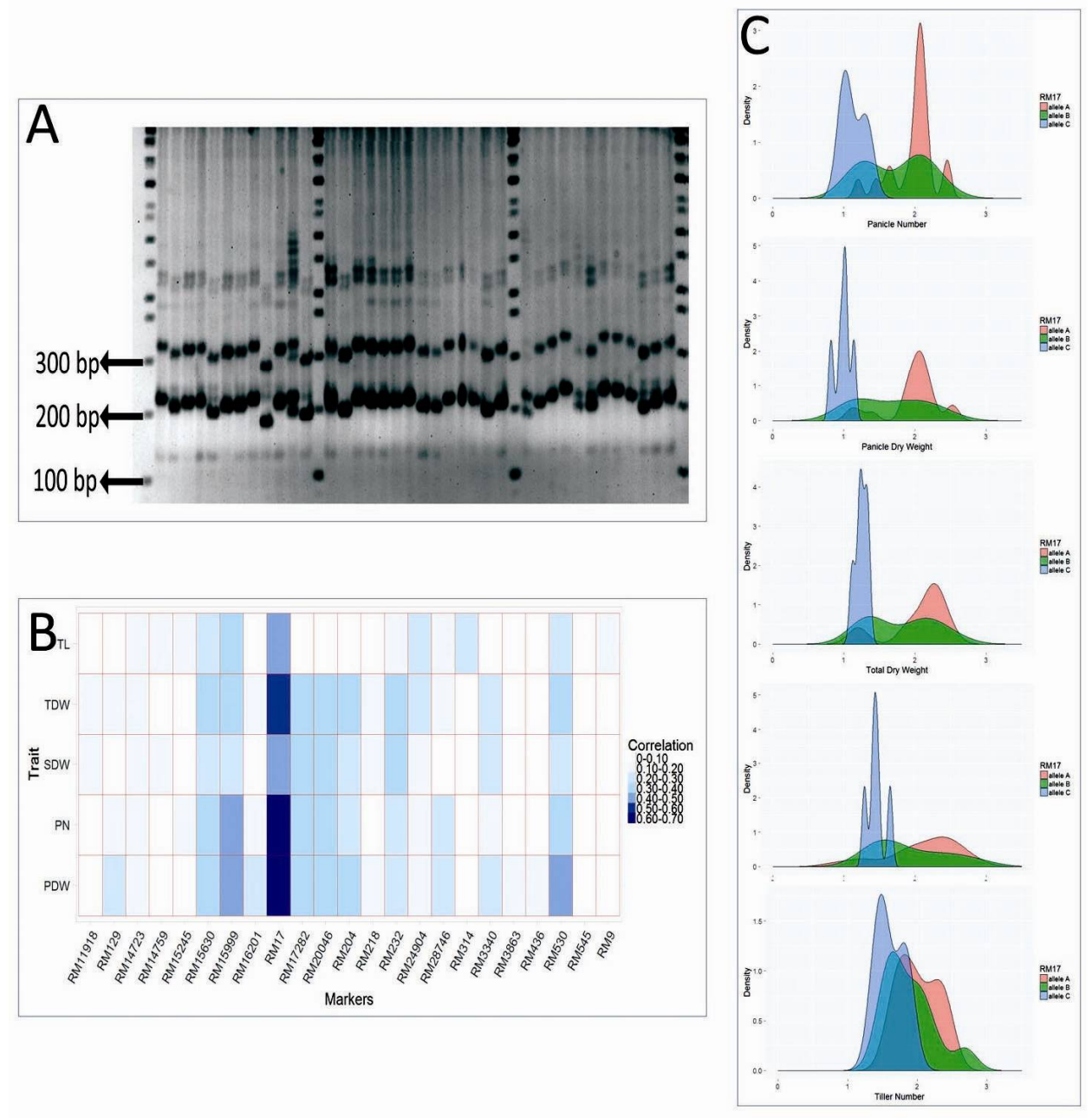

Fig. 3: A. PAGE gel picture of RM314 along with the ladder DNA, the size of the ladder DNAs are denoted using arrow sign. B. Correlation of markers with the traits ( $\mathrm{PN}=$ Panicle number, PDW = Panicle dry weight, SDW $=$ Straw dry weight, $\mathrm{TDW}=$ Total dry weight, $\mathrm{TL}=$ Tiller number $)$. C. Distribution of different alleles in different relative responses. Three different alleles were distributed distinctively across different phenotypic traits plasticity, including panicle number, panicle dry weight, total dry weight, straw dry weight and tiller number.

of the varieties were measured as a ratio of the low density planting and normal density planting (LD/ND). The average relative response of the panicle dry weight and panicle number were found to be 1.59 (59\% increase) and 1.71 (71\% increase) across 202 indigenous rice cultivars. There were no significant increase of harvest index in low density planting. These finding are compatible to previous conducted studies on phenotypic plasticity (Kikuchi et al. 2017). Finally we selected 10 genotypes which showed most plasticity in multiple traits. These 
accessions, are currently under investigation for validation in $\left[\mathrm{CO}_{2}\right]$ enriched environment, will facilitate the selection process of plant breeders for $\mathrm{e}\left[\mathrm{CO}_{2}\right]$ responsive varieties.

Another findings of our study is that cultivars which required more days for headings (late maturity group), showed better performance in low density planting in most of the traits we analyzed than cultivars of early maturity group. As late maturing cultivars grow for a longer time, so there is a higher chance for utilizing the assimilated carbons for reproductive and vegetative growth. Interestingly, the relative response of harvest index is higher for early maturing cultivars. This phenomenon can be attributed to the complex nature of the grain filling, which ultimately leads to panicle weight. At any given time, leaves of early maturing group cultivars are more close to senescence than late maturing group. As a consequence, there are higher chance of the early maturing groups to remobilize the assimilated carbohydrate for reproductive growth rather than vegetative growth, as growth of plant leaves are more likely to be terminated (Yang and Zhang 2006).

We also conducted a candidate gene-based analysis using simple sequence repeat (SSR) markers for identification of genes or SSR markers which are associated with the phenotypic plasticity. SSR markers were used due to their multiallelic nature, high variability and comparative abundance across the whole genome of rice. Phenotypic plasticity is the most possible causative trait of higher yield and biomass in low density planting as well as elevated $\mathrm{CO}_{2}\left(\left[\mathrm{eCO}_{2}\right]\right)$. These markers were chosen due to their close proximity to the loci of the 23 up regulated genes of rice in elevated $\left[\mathrm{CO}_{2}\right]$ (Fukayama et al. 2009, Fukayama et al. 2011) along with 3 QTLs of phenotypic plasticity (Kikuchi et al. 2017). After analyzing the marker-trait correlation we identified one particular marker, RM17, which is highly correlated with the traits. This marker is located at a close proximity to transcriptional activator HAP2 (AK073742), an up regulated gene in $\mathrm{e}\left[\mathrm{CO}_{2}\right]$ and $\mathrm{qER} 3$, an associated SNP of phenotypic plasticity. In rice, the target promoter of HAP2 family transcription factor is related to starch synthesis (Morita et al. 2015). Although this correlation needs further validation, our study indicated the presence of a hotspot of phenotypic plasticity in chromosome 12 and the possibility of a link of starch synthesis regulation with enhanced phenotypic plasticity of rice.

\section{Acknowledgement}

Funds for supporting the phenotypic work at BRRI from Iwate University (courtesy of Dr. H. Shimono) is gratefully acknowledged. Technical help from M. Nazrul Islam for the growth and observation of the phenotypic characters of the 
rice genotypes is also acknowledged. Authors also acknowledge the contribution of the BRRI GenBank for providing them with the rice genotype accessions 1-463.

\section{References}

Ainsworth EA, C Beier, C Calfapietra, R Ceulemans, M Durand-Tardif, GD Farquhar, DL Godbold, GR Hendrey, T Hickler and J Kaduk (2008) Next generation of elevated $\left[\mathrm{CO}_{2}\right]$ experiments with crops: a critical investment for feeding the future world. Plant, Cell \& Environment 31(9): 1317-1324.

Amin U, S Biswas, SM Elias, S Razzaque, T Haque, R Malo and ZI Seraj (2016) Enhanced salt tolerance conferred by the complete $2.3 \mathrm{~kb}$ cDNA of the rice vacuolar $\mathrm{Na}+\not \mathrm{H}+$ antiporter gene compared to $1.9 \mathrm{~kb}$ coding region with $5^{\prime} \mathrm{UTR}$ in transgenic lines of rice. Frontiers in Plant Science 7: 14.

Bishop KA, AM Betzelberger, SP Long and EA Ainsworth (2015) Is there potential to adapt soybean (Glycine max Merr.) to future $\left[\mathrm{CO}_{2}\right]$ ? An analysis of the yield response of 18 genotypes in free-air $\mathrm{CO}_{2}$ enrichment. Plant, Cell \& Environment 38(9): 17651774.

Bunce JA (2015) Elevated carbon dioxide effects on reproductive phenology and seed yield among soybean cultivars. Crop Science 55(1): 339-343.

Chaturvedi AK, RN Bahuguna, D Shah, M Pal and SK Jagadish (2017) High temperature stress during flowering and grain filling offsets beneficial impact of elevated $\mathrm{CO}_{2}$ on assimilate partitioning and sink-strength in rice. Scientific Reports 7(1): 8227.

Doyle JJ and Doyle JL (1987) A rapid DNA isolation procedure for small quantities of fresh leaf tissue. Phytochemical Bulletin 19: 11-15.

Fukayama H, T Fukuda, C Masumoto, Y Taniguchi, H Sakai, W Cheng, T Hasegawa and $\mathbf{M}$ Miyao (2009) Rice plant response to long term $\mathrm{CO}_{2}$ enrichment: Gene expression profiling. Plant Science 177(3): 203-210.

Fukayama H, M Sugino, T Fukuda, C Masumoto, Y Taniguchi, M Okada, R Sameshima, T Hatanaka, S Misoo and T Hasegawa (2011) Gene expression profiling of rice grown in free air $\mathrm{CO}_{2}$ enrichment (FACE) and elevated soil temperature. Field Crops Research 121(1): 195-199.

Hasegawa T, H Sakai, T Tokida, H Nakamura, C Zhu, Y Usui, M Yoshimoto, M Fukuoka, H Wakatsuki and N Katayanagi (2013) Rice cultivar responses to elevated $\mathrm{CO}_{2}$ at two free-air $\mathrm{CO}_{2}$ enrichment (FACE) sites in Japan. Functional Plant Biology 40(2): 148-159.

Jasim Aljumaili, S, MY Rafii, M Latif, SZ Sakimin, IW Arolu and G Miah (2018) Genetic diversity of aromatic rice germplasm revealed by SSR markers. BioMed. Research International Vol. 2018, Article ID: 7658032.

Kant, S, S Seneweera, J Rodin, M Materne, D Burch, SJ Rothstein and G Spangenberg (2012) Improving yield potential in crops under elevated $\mathrm{CO}_{2}$ : Integrating the photosynthetic and nitrogen utilization efficiencies. Frontiers in Plant Science 3: 162.

Kikuchi S, R Bheemanahalli, KS Jagadish, E Kumagai, Y Masuya, E Kuroda, C Raghavan, M Dingkuhn, A Abe and H Shimono (2017) Genome-wide association mapping for phenotypic plasticity in rice. Plant, Cell \& Environment 40(8): 1565-1575. 
Kumagai E, N Aoki, Y Masuya and H Shimono (2015) Phenotypic plasticity conditions the response of soybean seed yield to elevated atmospheric $\mathrm{CO}_{2}$ concentration. Plant Physiology 169(3): 2021-2029.

Leakey AD (2009) Rising atmospheric carbon dioxide concentration and the future of C4 crops for food and fuel. Proceedings of the Royal Society of London B: Biological Sciences 276(1666): 2333-2343.

Li P, A Sioson, SP Mane, A Ulanov, G Grothaus, LS Heath, T Murali, HJ Bohnert and R Grene (2006) Response diversity of Arabidopsis thaliana ecotypes in elevated $\left[\mathrm{CO}_{2}\right]$ in the field. Plant molecular biology 62(4-5): 593-609.

Liu K and SV Muse (2005) Power Marker : An integrated analysis environment for genetic marker analysis. Bioinformatics 21(9): 2128-2129.

Long SP (2014) We need winners in the race to increase photosynthesis in rice, whether from conventional breeding, biotechnology or both. Plant, Cell \& Environment 37(1): 19-21.

Long SP, EA Ainsworth, A Rogers and DR Ort (2004) Rising atmospheric carbon dioxide : Plants FACE the future. Annu. Rev. Plant Biol. 55: 591-628.

Molina-Montenegro MA, C Galleguillos, R Oses, IS Acuña-Rodríguez, P Lavín, J Gallardo-Cerda, C Torres-Díaz, B Diez, GE Pizarro and C Atala (2016) Adaptive phenotypic plasticity and competitive ability deployed under a climate change scenario may promote the invasion of Poa annua in Antarctica. Biological invasions 18(3): 603-618.

Morita R, M Sugino, T Hatanaka, S Misoo and H Fukayama (2015) $\mathrm{CO}_{2}$-responsive CONSTANS, CONSTANS-like, and time of chlorophyll a b binding protein expression 1 protein is a positive regulator of starch synthesis in vegetative organs of rice. Plant Physiology 167(4): 1321-1331.

Paleari L, E Movedi, G Cappelli, LT Wilson and R Confalonieri (2017) Surfing parameter hyperspaces under climate change scenarios to design future rice ideotypes. Global change biology 23(11): 4651-4662.

Patterson H and E Williams (1976) A new class of resolvable incomplete block designs. Biometrika 63(1): 83-92.

Price TD, A Qvarnström and DE Irwin (2003) The role of phenotypic plasticity in driving genetic evolution. Proceedings of the Royal Society of London B: Biological Sciences 270(1523): 1433-1440.

Ray DK, ND Mueller, PC West and JA Foley (2013) Yield trends are insufficient to double global crop production by 2050. PloS one 8(6): e66428.

Shimono H (2011) Rice genotypes that respond strongly to elevated $\mathrm{CO}_{2}$ also respond strongly to low planting density. Agriculture, Ecosystems \& Environment 141(1-2): 240-243.

Shimono H and M Okada (2013) Plasticity of rice tiller production is related to genotypic variation in the biomass response to elevated atmospheric $\mathrm{CO}_{2}$ concentration and low temperatures during vegetative growth. Environmental and experimental botany 87: 227-234. 
Shimono H, M Okada, Y Yamakawa, H Nakamura, K Kobayashi and T Hasegawa (2008) Genotypic variation in rice yield enhancement by elevated $\mathrm{CO}_{2}$ relates to growth before heading, and not to maturity group. Journal of Experimental Botany 60(2): 523532.

Shimono H, Y Ozaki, KS Jagadish, H Sakai, Y Usui, T Hasegawa, E Kumagai, H Nakano and S Yoshinaga (2014) Planting geometry as a pre-screening technique for identifying $\mathrm{CO}_{2}$ responsive rice genotypes : A case study of panicle number. Physiologia plantarum 152(3): 520-528.

Srinivasan V, P Kumar and SP Long (2017) Decreasing, not increasing, leaf area will raise crop yields under global atmospheric change. Global Change Biology 23(4): 16261635.

Team RC (2013) R: A language and environment for statistical computing. http:/wwww.rproject.org.

Tausz-Posch S, RW Dempsey, S Seneweera, RM Norton, G Fitzgerald and M Tausz (2015) Does a freely tillering wheat cultivar benefit more from elevated CO2 than a restricted tillering cultivar in a water-limited environment? European Journal of Agronomy 64: 21-28.

Wickham H (2009). ggplot2: elegant graphics for data analysis, Springer Science \& Business Media.

Yang J and J Zhang (2006) Grain filling of cereals under soil drying. New phytologist 169(2): 223-236.

Zhang T, X Yang, H Wang, Y Li and Q Ye (2014) Climatic and technological ceilings for Chinese rice stagnation based on yield gaps and yield trend pattern analysis. Global change biology 20(4): 1289-1298.

Zhu C, J Zhu, J Cao, Q Jiang, G Liu and LH Ziska (2014) Biochemical and molecular characteristics of leaf photosynthesis and relative seed yield of two contrasting rice cultivars in response to elevated [CO $\mathrm{CO}_{2}$. Journal of Experimental Botany 65(20): 60496056.

Zhu, X-G, SP Long and DR Ort (2010) Improving photosynthetic efficiency for greater yield. Annual Review of Plant Biology 61: 235-261.

Ziska L and D Blumenthal (2007) Empirical selection of cultivated oat in response to rising atmospheric carbon dioxide. Crop Science 47(4): 1547-1552.

Ziska LH (2008) Three-year field evaluation of early and late 20th century spring wheat cultivars to projected increases in atmospheric carbon dioxide. Field Crops Research 108(1): 54-59.

Ziska LH, JA Bunce, H Shimono, DR Gealy, JT Baker, PC Newton, MP Reynolds, KS Jagadish, C Zhu and M Howden (2012) Food security and climate change : On the potential to adapt global crop production by active selection to rising atmospheric carbon dioxide. Proceedings of the Royal Society of London B: Biological Sciences: 279(1745): 4097-4105. 